\title{
Relationship between primary nocturnal enuresis and geometry of nasal cavities
}

\section{Primer nokturnal enürezis ve nazal kavite geometrisi arasindaki iliş̧ki}

\author{
Yavuz Güler'1D, Rukiye Güler² ${ }^{2}$ \\ Department of Otolaryngology, Balıklıg̈l State Hospital, Şanlıurfa, Turkey \\ Department of Otolaryngology, Şanlıurfa Training and Research Hospital, Şanliurfa, Turkey
}

\section{ABSTRACT}

Objectives: In this study, we aimed to investigate the possible relationship between primary nocturnal enuresis (PNE) and the geometry of nasal cavities in children.

Patients and Methods: Between 01.06.2018 and 31.07.2018, a total of 150 patients (78 males, 72 females, mean ages $7.6 \pm 1.8$ years, range, 5-12.5 years) who were admitted to the Ear, Nose, and Throat outpatient clinics of a secondary care hospital were included. The patients were divided into two groups as those with PNE (PNE (+), n=78) and those without PNE (PNE (-), $\mathrm{n}=72$ ). Both groups were compared in terms of age, sex, height, weight, body mass index (BMI) and acoustic rhinometry measurements (ARMs) (MCA-1, MCA-2 and VOL 0-5).

Results: There was no significant difference in any of the parameters evaluated between the groups. However, the MCA-1, MCA-2, and VOL 0-5 values were significantly lower in the PNE (+) group than the PNE (-) group.

Conclusion: Nasal patency was lower in patients with PNE in our study. Therefore, we recommend that PNE patients should be evaluated by the otolaryngologist for nasal obstruction before the initiation of medical treatment.

Keywords: Acoustic rhinometry, etiology, nasal obstruction, primary nocturnal enuresis.

Nocturnal enuresis is defined as bedwetting during sleep without any urinary system pathologies such as cystitis, urethritis, bladder dysfunction with the condition being repeated at least two times a week for
$\ddot{O} Z$

Amaç: $\mathrm{Bu}$ çalışmada çocuklarda primer nokturnal enürezis (PNE) ve nazal kavite geometrisi arasındaki muhtemel ilişki araştırıldı.

Hastalar ve Yöntemler: 01.06.2018 - 31.07.2018 tarihleri arasında ikinci basamak bir hastanenin Kulak, Burun, Boğaz polikliniklerine başvuran toplam 150 hasta (78 erkek, 72 kadın; ort. yaş $7.6 \pm 1.8$ yıl; dağılım, 5-12.5 yıl) çalışmaya alındı. Hastalar PNE olanlar (PNE (+), n=78) ve PNE olmayanlar (PNE (-), n=72) olmak üzere iki gruba ayrıldı. Her iki grup yaş, cinsiyet, boy, kilo, vücut kütle indeksi (VKİ) ve akustik rinometri ölçümleri (ARM) (MCA-1, MCA-2 ve VOL 0-5) açısından karşılaştırıldı.

Bulgular: Gruplar arasında değerlendirilen parametrelerin hiçbirinde anlamlı bir fark yoktu. Ancak, MCA-1, MCA-2 ve VOL 0-5 değerleri PNE (-) gruba kıyasla, PNE (+) grupta anlamlı olarak düşüktü.

Sonuç: Çalışmamızda nazal açıklık PNE hastalarında daha düşüktü. Bu nedenle, PNE hastalarının medikal tedaviye başlamadan önce nazal obstrüksiyon açısından otolaringolog tarafından değerlendirilmesini önermekteyiz.

Anahtar sözcükler: Akustik rinometri, etyoloji, nazal tıkanıklık, primer nokturnal enürezis,.

Received: September 08, 2018 Accepted: January 16, 2019 Published online: March 28, 2019

Correspondence: Yavuz Güler, MD. Balıklıg̈l Devlet Hastanesi, Kulak Burun Boğaz Hastalıkları Kliniği, 63050 Balıklıgöl, Şanlıurfa, Turkey. e-mail: dryavuzguler@hotmail.com 
six months of dryness. Primary type constitutes the vast majority of nocturnal enuresis. It has been reported that PNE has been seen in $15 \%$ of children aged five years, in $10 \%$ of children aged 10 years, and in $1 \%$ of children aged 15 years. $^{[2]}$

The etiology of PNE has not been clarified, yet. However, genetic susceptibility, delay of maturation, psychological causes, sleep disorders and upper airway obstructive pathologies are emphasized in the etiology. Nonetheless, contradictory results have been reported in studies on the role of upper airway obstructive pathologies in the etiology of PNE, such as adenoid hypertrophy, turbinate hypertrophy, allergic rhinitis and nasal septum deviation. While some authors have advocated the role of upper airway obstruction in PNE etiology, some others have not. ${ }^{[3-6]}$ Furthermore, to the best of our knowledge, there is no study regarding this subject in which the degree of nasal obstruction is determined by objective methods.

Acoustic rhinometry (ARM) is a device which can objectively measure nasal cavities. The functioning principle is based on the reflection of the acoustic signals sent to the nasal cavity by multiplying the nasal structures. With the help of reflected acoustic signals, the cross-sectional areas and volumes of the desired region can be calculated with in the nose. In the measurements carried out by ARM, minimal cross-sectional area 1 (MCA-1), which shows the cross-sectional area of the isthmus nasi area, that is the narrowest region of the nose most frequently used, minimal cross-sectional area 2 (MCA-2) showing the cross-sectional area of the inferior concha head region the second narrowest zone of the nose, and intranasal volume up to $5 \mathrm{~cm}$ from nares (VOL $0-5$ ) values have been used. ${ }^{[7]}$ In previous studies, ARM has been reported as a reliable method for objective examination of nasal cavities. ${ }^{[8]}$

In this study, we aimed to investigate the possible relationship between PNE and the geometry of nasal cavities in children.

\section{PATIENTS AND METHODS}

In this case-control study, a total of randomly selected 150 patients (78 males, 72 females, mean ages $7.6 \pm 1.8$ years, range, 5-12.5 years) who were admitted to the Ear, Nose, and Throat outpatient clinics of a Balıklıgöl State Hospital between 01.06.2018-31.07.2018 were included. A written informed consent was obtained from each patient. The study protocol was approved by the Harran University Medicine Faculty Ethics Committee. The study was conducted in accordance with the principles of the Declaration of Helsinki.

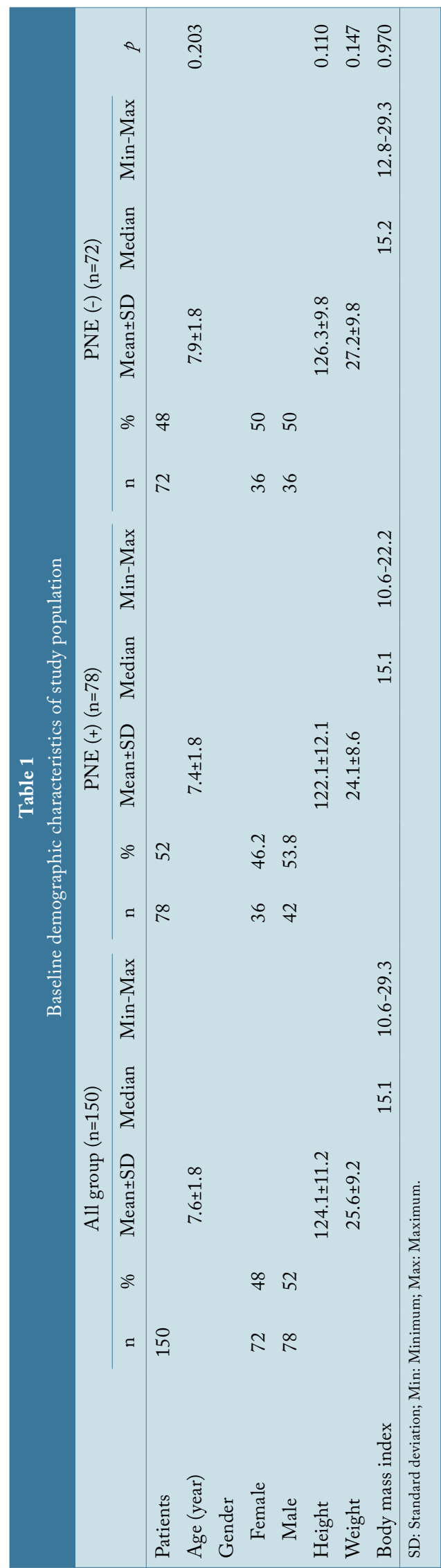


The patients were divided into two groups as those with PNE (PNE (+), n=78) and those without PNE (PNE (-), $n=72$ ). In addition to the detailed ENT examinations, nasal endoscopic examinations and ARM tests were performed to all patients. Harpenden stadiometer (Tartı Medikal Dı̧̧ Ticaret ve Pazarlama Ltd. Şti., Istanbul, Turkey) was used as the heightmeasuring instrument sensitive to $\mathrm{mm}$. The weight measurements were done using an electronic weigher sensitive to $10 \mathrm{~g}$. Data including age, sex, weight, and body mass index (BMI) were recorded.

Primary nocturnal enuresis diagnosis was based on the American Psychiatric Association Diagnostic and Statistical Manual of Mental Disorders, Fourth Edition (DSM-IV) criteria. $^{[9]}$ These criteria were as follows: (i) repeated voiding of urine into bed or clothes; (ii) repetition of this behavior at least twice a week and duration for at least three months; (iii) chronological age is at least five years; and (iv) the behavior is not due to the direct physiological effect of a substance (e.g., a diuretic) or a general medical condition (e.g., diabetes, spina bifida, and a seizure disorder).

Exclusion criteria were as follows: (i) congenital anomalies, (ii) mental retardation, (iii) chronic systemic diseases, (iv) central nervous system diseases and neurogenic bladder, (v) cystitis, (vi) hypospadias, epispadias, (vii) acute/chronic sinusitis, (viii) acute upper respiratory tract infections, and (ix) adenoid hypertrophy (more than 50\% obstruction in nasal endoscopic examination).

\section{Acoustic rhinometry measurements}

All ARMs were performed using the A1 Acoustic rhinometer (GM Instrument; Scotland, United Kingdom) device. All measurements of all patients were performed in a room with a quiet ambient, far from environmental impacts, and a temperature of $25^{\circ} \mathrm{C}$. The patients were asked to undergo a mouth respiration session after being seated for five $\min$ in a seat, and four measurements were taken repeatedly.
The test was considered successful, if the gap between the measurements was less than $10 \%$. The procedure was applied to both nostrils. The arithmetic mean of the measurements from the right and left nostrils were, then, calculated and recorded.

\section{Statistical analysis}

Statistical analysis was performed using the IBM SPSS version 21.0 (IBM Corp., Armonk, NY, USA). Descriptive statistics were expressed in mean \pm standard deviation (SD) and median (min-max) or number and frequency. The difference in sex distribution of the groups was assessed by Chi-square test. The Kolmogorov-Smirnov test was used to determine whether the parameters were normal. The Student's t-test was used for the variables with normal distribution and the Mann-Whitney $U$ test was used for the variables with non-normal distribution between the groups. A $p$ value of $\leq 0.05$ was considered statistically significant.

\section{RESULTS}

Of the PNE (-) group, 36 (46.2\%) were females with a mean age of $7.9 \pm 1.8$ (range, 5.1 to 12.5 ) years. Of the PNE (+) group, $36(50 \%)$ were females with mean age of $7.4 \pm 1.8$ (range, 5.1 to 11.3 ) years. The mean height, weight, and BMI of the PNE (+) group were $122.1 \pm 12.1 \mathrm{~cm}, 24.1 \pm 8.6 \mathrm{~kg}$, and $15.1 \mathrm{~kg} / \mathrm{cm}^{2}$, respectively. These rates were $126.3 \pm 9.8 \mathrm{~cm}, 27.2 \pm 9.8$ $\mathrm{kg}$, and $15.2 \mathrm{~kg} / \mathrm{cm}^{2}$, respectively in the PNE (-) group. There was no significant difference in terms of age, sex, height, weight, and BMI values between the groups (Table 1).

The mean MCA-1, MCA-2, and VOL 0-5 values of the PNE (+) group were $0.4 \pm 0.1 \mathrm{~cm}^{2}, 1.0 \pm 0.5 \mathrm{~cm}^{2}$, and $5.0 \pm 1.2 \mathrm{~cm}^{3}$, respectively. The mean MCA-1, MCA2 , and VOL $0-5$ values of the PNE (-) group were $0.5 \pm 0.1 \mathrm{~cm}^{2}, 1.3 \pm 0.6 \mathrm{~cm}^{2}$, and $5.7 \pm 1.5 \mathrm{~cm}^{3}$, respectively. The MCA-1, MCA-2, and VOL 0-5 values were

\begin{tabular}{|c|c|c|c|c|}
\hline \multicolumn{5}{|c|}{$\begin{array}{l}\text { Table } 2 \\
5 \text { values in PNE }\end{array}$} \\
\hline & All group & PNE (+) & PNE (-) & \\
\hline & Mean \pm SD & Mean \pm SD & Mean \pm SD & $p$ \\
\hline $\operatorname{MCA} 1\left(\mathrm{~cm}^{2}\right)$ & $43.2 \pm 1.0$ & $41.0 \pm 8.1$ & $45.6 \pm 8.0$ & $0.015^{*}$ \\
\hline MCA $2\left(\mathrm{~cm}^{2}\right)$ & $109.4 \pm 6.7$ & $94.3 \pm 46.9$ & $125.7 \pm 64.8$ & $0.018^{*}$ \\
\hline Vol 0-5 $\left(\mathrm{cm}^{3}\right)$ & $5.4 \pm 1.4$ & $5.1 \pm 1.4$ & $5.8 \pm 1.4$ & $0.042^{*}$ \\
\hline
\end{tabular}




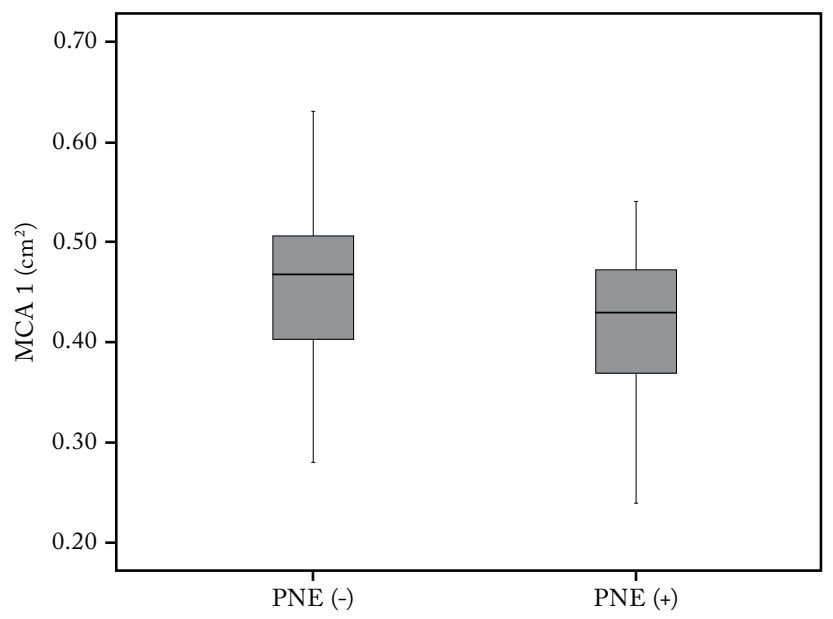

Figure 1. The distribution of MCA-1 values between groups. MCA 1: Minimal cross-sectional area 1; PNE: Primary nocturnal enuresis.

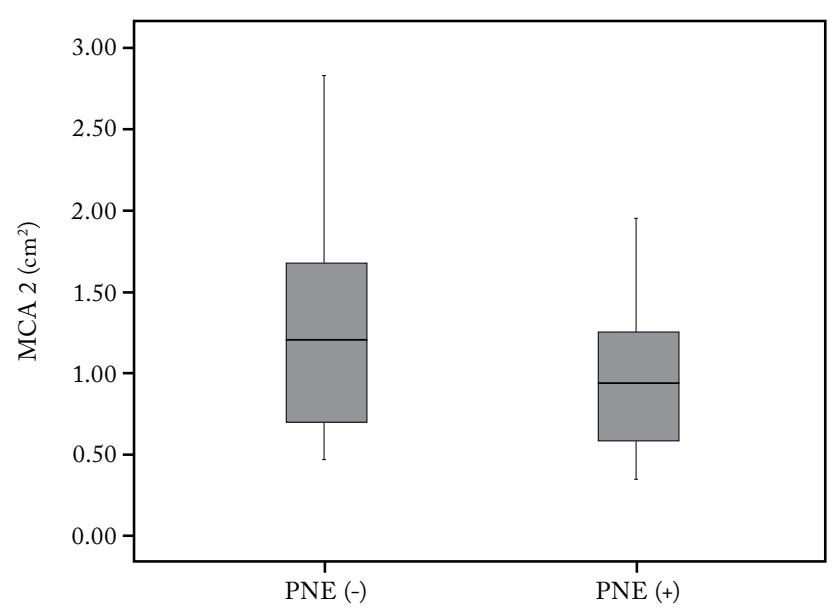

Figure 2. The distribution of MCA-2 values between groups. MCA 2: Minimal cross-sectional area 2; PNE: Primary nocturnal enuresis.

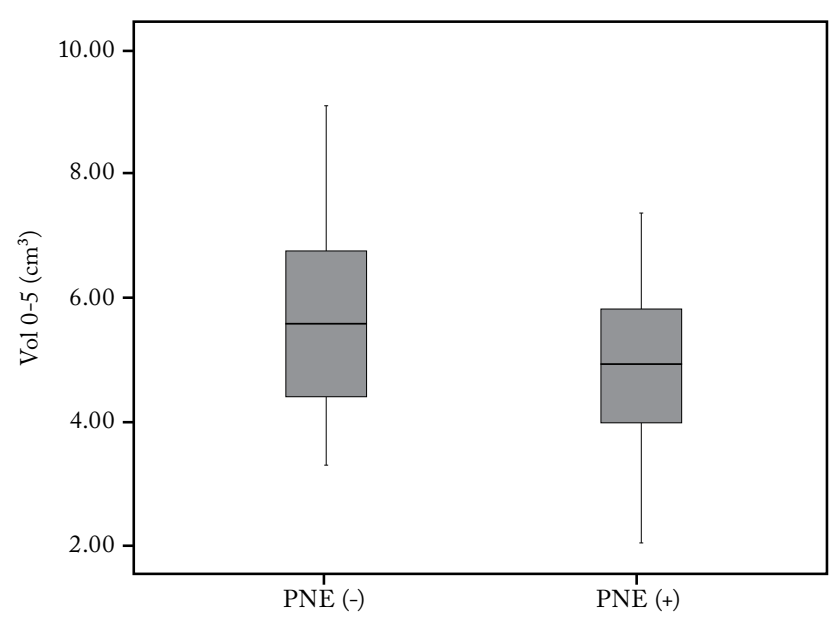

Figure 3. The distribution of VOL 0-5 values between groups. VOL 0-5: Volume up to $5 \mathrm{~cm}$ from nares; PNE: Primary nocturnal enuresis. significantly lower in the PNE (+) group than in the PNE (-) group (Table 2).

The distribution of MCA-1, MCA-2, and VOL 0-5 values between the groups is respectively shown in Figures 1, 2, and 3 .

\section{DISCUSSION}

Primary nocturnal enuresis is defined as bedwetting without any urinary system pathologies in children over five years old. Its prevalence varies between $8.2 \%$ and $37 \%$ worldwide. ${ }^{[10,11]}$ Primary nocturnal enuresis may lead to loss of self-confidence in children and psychological problems in the family. Also, it has been shown that, if left untreated, it is associated with many psychiatric problems such as psychosomatic disorders and depression in the adulthood. ${ }^{[12]}$

In recent years, intensive studies have been carried out on the role of pathologies causing upper airway obstruction in etiology of PNE. The most common causes of childhood upper airway obstruction include pathologies such as adenoid hypertrophy, allergic rhinitis, nasal septum deviations, and inferior concha hypertrophy. The ARM device is often preferred when measuring the degree of nasal obstruction caused by these pathologies. In addition, ARM is an objective method in evaluating the response of these obstructive pathologies to surgical and medical treatments.

However, problems can arise in inter-group comparisons, as the measurements based on the ARM can be affected by age, sex, height, weight, and BMI values of the individual. This can affect the results of the study negatively. As there was no difference between the PNE (+) group and PNE (-) control group in terms of age, sex, height, weight, and BMI in our study, this was a factor increasing the reliability of our results. Nevertheless, the reliability of ARM measurements in the degree of showing obstruction in nasopharyngeal pathologies such as adenoid vegetation due to the movement of the palatum molle is another debate. ${ }^{[13]}$ As a matter of fact, patients included in our study were not evaluated for nasopharyngeal pathology. This is one of the limitations of our study. However, exclusion of patient with adenoid hypertrophy was a factor that increased the reliability of our results.

Controversial results have been reported in the literature regarding the role of upper airway obstructive pathologies in the etiology of PNE. In a study conducted by Aydin et al. ${ }^{[3]}$ including 1,132 children whose ages ranged from 5 to 14 years, there was no significant difference in adenoid vegetation and PNE frequency. Contrary to this study, Balaban et al. ${ }^{[4]}$ included 79 PNE 
and 64 control patients in their study and reported that upper airway obstruction was seen more in the PNE group than the control group. However, in their study, only adenoid and tonsillar hypertrophy were evaluated among obstructive pathologies of the upper respiratory tract. In another study, Karakas et al. ${ }^{[5]}$ compared 112 PNE patients with 113 control groups in terms of upper airway pathologies. The authors reported that adenoid hypertrophy and nasal septal deviation were more common in PNE patients, while tonsillar hypertrophy, allergic rhinitis, and turbinate hypertrophy were found to be equal in both groups. Contrary to this study, Tsai et al. ${ }^{[6]}$ found that allergic rhinitis significantly increased the incidence of PNE in their study including 8,616 children from the Taiwanese National Health Insurance Research Database between 2007 and 2012.

In addition, Kovacevic et al. ${ }^{[14]}$ reported that $43.5 \%$ of 46 patients became dry after adenotonsillectomy. In another study, Weider et al. ${ }^{[15]}$ found that by means of surgical removal of upper airway obstruction, about $76 \%$ of the PNE complaints were treated.

To the best of our knowledge, there is no study in children that reveals the objective role of nasal obstruction in the etiology of PNE. Subjective analysis of nasal patency is usually performed by the clinician request to perform self-evaluation of the patients with the help of questionnaire or visual analog scale in addition to physical examination. There is a risk of error with high margin in studies conducted with subjective criteria particularly in children, which are difficult to make self-evaluations. Therefore, our study was carried out by an ARM device that is non-invasive and requires minimal patient cooperation, which objectively demonstrates nasal patency. ${ }^{[16]}$

In our present study, both groups were compared in terms of values of MCA- 1 showing the cross-sectional area of the nasal valve area, MCA-2 showing the crosssectional area of the inferior concha head area, and VOL 0-5 indicating the nasal volume between $0-5 \mathrm{~cm}$ in the nose. As a result, the PNE (+) group was found to have significantly lower MCA-1, MCA-2, and VOL 0-5 values in the patients, compared to the healthy controls. This result suggests that nasal obstruction plays a role in the etiology of PNE.

Furthermore, it is well-known that children with PNE have difficulty in awakening to their toilet needs. ${ }^{[17]}$ Wille ${ }^{[18]}$ reported that sleep of children with PNE was deeper. It is thought that decrease in sleep quality due to nasal obstruction, additional effort for breathing and depression of oxygen levels due to obstructive respiratory distress and, as a result of these difficulties, in waking up to the toilet may lead to PNE.
As a matter of fact, Jönson Ring et al. ${ }^{[19]}$ reported that the oxygen desaturation index was slightly higher in children with nocturnal enuresis compared to healthy controls. However, Balaban et al. $^{[4]}$ in a study of 79 nocturnal enuresis patients and 64 controls reported that children with nocturnal enuresis had deeper sleep and higher arousal levels due to hypoxia caused by upper airway obstruction.

Another possible mechanism that should be considered is how nasal obstruction affects renal functions. There is a very limited number of studies in the literature to clarify this issue. Nocturnal intermittent oxygen desaturation due to nasal obstruction may play a role in the etiology of PNE by increasing the rate of renal glomerular filtration or reducing reabsorption in the distal tubules. In their study, Kinebuchi et al. ${ }^{[20]}$ reported that upper airway obstruction increased the rate of renal glomerular filtration and that the rate of glomerular filtration with treatment was significantly lower in those patients than in those who did not. Based on this finding, we believe that nasal obstruction plays a role in the etiology of PNE by increasing glomerular filtration rate due to both difficulties in awakening and oxygen desaturation in children. However, previous studies have not clearly shown how the nasal obstruction plays a role with the mechanism in the etiology of PNE.

In conclusion, the nasal patency was significantly lower in children with PNE in our study. To the best of our knowledge, this is the first study with objective data to support the notion that upper respiratory tract obstructive pathologies play a role in the etiology of PNE. We, therefore, recommend that patients with PNE should be evaluated by the otolaryngologist for nasal obstruction before the initiation of medical treatment. Nonetheless, further large-scale studies are needed to elucidate this issue.

\section{Declaration of conflicting interests}

The authors declared no conflicts of interest with respect to the authorship and/or publication of this article.

\section{Funding}

The authors received no financial support for the research and/or authorship of this article.

\section{REFERENCES}

1. Nørgaard JP, van Gool JD, Hjälmås K, Djurhuus JC, Hellström AL. Standardization and definitions in lower urinary tract dysfunction in children. International Children's Continence Society. Br J Urol 1998;81:1-16.

2. Lawless MR, McElderry DH. Nocturnal enuresis: current concepts. Pediatr Rev 2001;22:399-407. 
3. Aydin S, Sanli A, Celebi O, Tasdemir O, Paksoy M, Eken $\mathrm{M}$, et al. Prevalence of adenoid hypertrophy and nocturnal enuresis in primary school children in Istanbul, Turkey. Int J Pediatr Otorhinolaryngol 2008;72:665-8.

4. Balaban M, Aktas A, Sevinc C, Yucetas U. The relationship of enuresis nocturna and adenoid hypertrophy. Arch Ital Urol Androl 2016;88:111-4.

5. Karakas HB, Mazlumoglu MR, Simsek E. The role of upper airway obstruction and snoring in the etiology of monosymptomatic nocturnal enuresis in children. Eur Arch Otorhinolaryngol 2017;274:2959-63.

6. Tsai JD, Chen HJ, Ku MS, Chen SM, Hsu CC, Tung $\mathrm{MC}$, et al. Association between allergic disease, sleepdisordered breathing, and childhood nocturnal enuresis: a population-based case-control study. Pediatr Nephrol 2017;32:2293-301.

7. Huizing EH, de Groot JAM, editors. Functional reconstruction nasal surgery. Stuttgart: Thieme; 2003.

8. Numminen J, Dastidar P, Heinonen T, Karhuketo T, Rautiainen M. Reliability of acoustic rhinometry. Respir Med 2003;97:421-7.

9. American Psychiatric Association. Diagnostic and Statistical Manual of Mental Disorders (DSM-5). 4th ed. Washington: American Psychiatry Press; 1995.

10. Choudhary B, Patil R, Bhatt GC, Pakhare AP, Goyal A, Aswin P, et al. Association of sleep disordered breathing with mono-symptomatic nocturnal enuresis: a study among school children of central India. PLoS One 2016;11:e0155808.

11. Anyanwu OU, Ibekwe RC, Orji ML. Nocturnal Enuresis among Nigerian Children and its Association with Sleep, Behavior and School Performance. Indian Pediatr
2015;52:587-9.

12. Strömgren A, Thomsen PH. Personality traits in young adults with a history of conditioning-treated childhood enuresis. Acta Psychiatr Scand 1990;81:538-41.

13. Riechelmann H, O'Connell JM, Rheinheimer MC, Wolfensberger M, Mann WJ. The role of acoustic rhinometry in the diagnosis of adenoidal hypertrophy in pre-school children. Eur J Pediatr 1999;158:38-41.

14. Kovacevic L, Wolfe-Christensen C, Lu H, Toton M, Mirkovic J, Thottam PJ, et al. Why does adenotonsillectomy not correct enuresis in all children with sleep disordered breathing? J Urol 2014;191:1592-6.

15. Weider DJ, Sateia MJ, West RP. Nocturnal enuresis in children with upper airway obstruction. Otolaryngol Head Neck Surg 1991;105:427-32.

16. Priftis KN, Papadimitriou N, Anthracopoulos MB. Should we perform objective assessment of nasal obstruction in children with chronic rhinitis? J Pediatr (Rio J) 2012;88:374-6.

17. Ergüven M, Çelik Y, Deveci M, Yıldız N. Etiological risk factors in primary nocturnal enuresis. Türk Pediatri Arşivi 2004;39:83-7.

18. Wille S. Comparison of desmopressin and enuresis alarm for nocturnal enuresis. Arch Dis Child 1986;61:30-3.

19. Jönson Ring I, Markström A, Bazargani F, Nevéus T. Sleep disordered breathing in enuretic children and controls. J Pediatr Urol 2017;13:620.

20. Kinebuchi S, Kazama JJ, Satoh M, Sakai K, Nakayama H, Yoshizawa H, et al. Short-term use of continuous positive airway pressure ameliorates glomerular hyperfiltration in patients with obstructive sleep apnoea syndrome. Clin Sci (Lond) 2004;107:317-22. 